\title{
A Wii-controlled safety device for electric chainsaws
}

\author{
R. Gubiani, ${ }^{1}$ G. Pergher, ${ }^{1}$ S.R.S. Cividino, ${ }^{1}$ R. Lombardo, ${ }^{2}$ F. Blanchini ${ }^{2}$ \\ 'University of Udine, Dept. DISA, Udine, Italy; ${ }^{2}$ Innovactors, Udine, Italy
}

\begin{abstract}
Forestry continues to represent one of the most hazardous economic sectors of human activity, and historically, the operation of chainsaws has mainly been restricted to professional lumberjacks. In recent years, because of low cost, chainsaws have become popular among unprofessionals, e.g. for cutting firewood and trimming trees. Serious or lethal lesions due to the use of chainsaws or electric chainsaws are often observed by traumatologists or forensic pathologists. Such serious accidents often occur during occupational activities and are essentially due to kickback or uncorrected use of the tool, or when the operator falls down losing the control of the implement. A new device in order to stop a cutting chain was developed and adapted to an electric chainsaw. The device is based on a Wiimote controller (Nintendo ${ }^{\mathrm{TM}}$ ), including two accelerometers and two gyroscopes for detecting rotation and inclination. A Bluetooth wireless technology is used to transfer data to a portable computer. The data collected about linear and angular acceleration are filtered by an algorithm, based on the Euclid norm, capable to distinguishing between normal movements and dangerous chainsaw movements. The result show a good answer to device and when happen a dangerous situation an alarm signal is sent back to the implement in order to stop the cutting chain. The device show a correct behavior in tested dangerous situations and is envisaged to extend to combustion engine chainsaws, as well as to other portable equipment used in agriculture and forestry operations and for this objectives were patented.
\end{abstract}

\section{Introduction}

Forestry continues to represent one of the most hazardous sectors of human activity; however, in the last years the scenario has changed. Historically, the use of chainsaws has mainly been restricted to profes-

Correspondence: Rino Gubiani, University of Udine, Dept. DISA, Via delle scienze 208, 33100 Udine, Italy.

Tel. -39.0432.558656

E-mail corresponding: Agricolturasicura@gmail.com,

rino.gubiani@uniud.it.

Key words: safety, chainsaw, fatal injuries, electronic device.

CC Copyright R. Gubiani et al., 2013

Licensee PAGEPress, Italy

Journal of Agricultural Engineering 2013; XLIV(s2):e138

doi:10.4081/jae.2013.s2.e138

This article is distributed under the terms of the Creative Commons Attribution Noncommercial License (by-nc 3.0) which permits any noncommercial use, distribution, and reproduction in any medium, provided the original author(s) and source are credited. sional lumberjacks, but in recent years, low-cost models have become popular among unprofessionals, e.g. for cutting firewood and trimming trees. Today, over 300000 chainsaws are sold annually in Italy, while many millions of older models are still in use. The U. S. Bureau of Labour Statistics reported that logging was causing $26 \%$ more frequent injures than general industries (Lefort et al., 1999). Accident rates in Sweden among chainsaw operators have been reported to be four times higher than among logging-machine operators (Axelsson, 1998). A German study (1994-1995) found that about $15 \%$ of all injures to forestry workers were the direct result of chainsaws (Hartfield , 1997). In the Southeastern United States a study showed that manual chainsaw delimbing, i.e. the cutting of branches from stems in felled trees, was the most hazardous activity in partial mechanized logging operations (Shaffer and Milburn, 1999). In Lousiana a study showed that tools and equipment (including chainsaw) were responsible for $19 \%$ of the injuries to the body in logging sector (Lefort et al., 1999).

In Italy, Spinelli et al. (2010) reported that operators often do not employ a safe technique for starting chainsaws, and do not correctly use PPE (personal protection equipment). Accidents research showed the chainsaw accidents is very high frequency than other operations as a skidding, tending or workplace conditions (Potocnik et al., 2009).

Modern chainsaws incorporate numerous safety features to protect the operator from kickback (i.e., the swift reaction upward movement of the chainsaw bar, especially when used with its tip, or "nose") and other hazardous events (particularly when the operator falls down losing the control of the implement). However, such features may be ineffective when correct working procedures are disregarded or even ignored (which often is the case of unprofessional operators). Even the newest models possess, however, some inherent dangers associated with their operation that could result in serious and sometime fatal injuries. Serious or lethal lesions due to the use of chainsaws or electric chainsaws are often observed by traumatologists or forensic pathologists. Such serious accidents often occur during occupational activities, or more rarely during suicidal events. For this kind of accidents, safety protection is possible only if the cutting chain is stopped because often the helmet not is sufficient to safety of kind of accident. The cutting chain is stopped only by activation to chain brake.

Many researchers have tried to set up a system designed to stop the chainsaw when the operator is moving the chainsaw in dangerous mode. One system proposes a capacitive sensor to detect human proximity near the guide bar and chain of a chainsaw. The capacitance sensors are measured using a carrier frequency method and the developed system provides information about human proximity at least for every $0.2 \mathrm{~s}$ and hence enables the control unit to react in real time. The system successfully distinguishes between proximity of the human body and wood. The developed system senses human proximity up to $15 \mathrm{~cm}$ from the chainsaw (Zangl and Bretterklieber, 2008).

Others researches have set up a brake on electric chainsaw where in that the electric motor is an electronically commutated electric motor having at least three coil windings, and at least one of the rundown and kickback brake and control means adapted to disconnect a driving voltage from each of said motor coil windings except at least one of them and apply a controlled resistive connection across each of said motor coil windings (Jordan et al., 2012). 
Until now, none of these systems reached commercial development, probably due to false response patterns that may decrease the work capacity of the operator. Only Husqvarna has adopted a system called TrioBrake ${ }^{\mathrm{TM}}$; it is a safety system where the chain brake can be activated in a third way - with the right hand besides the two customary ways. TrioBrake $^{\mathrm{TM}}$ can provide extra protection under situations where a regular chain brake would fail to provide adequate protection. This system forces the worker to assume a more ergonomic position with the body.

The objective of this study has been the development and realization of a new integrated safety system for chainsaws.

\section{Methodology}

A new device devised to stop a cutting chain was developed and adapted to an electric chainsaw. The goals to develop this device were:

a) the device must block the cutting chain when a mistake is identified in chainsaw behavior;

b) the device can be adopted in other handheld power equipment (drills, hedge trimmers), including chainsaws powered by 2 -stroke engines;

c) device must have a low cost.

The device is based on a Wiimote controller (Nintendo ${ }^{\mathrm{TM}}$ ), including two accelerometers and two gyroscopes for detecting rotation and inclination and thus solve b) and c) goals.

The main problem in a) goal is to identify the mistake in chainsaw behavior and to solve this we had follow path showed in Figure 2 .

A Bluetooth wireless technology is used to transfer data to a portable computer. The data collected about linear and angular acceleration are filtered by an algorithm, based on the Euclid norm, capable to distinguishing between normal movements and dangerous chainsaw movements.

In all chainsaws the chain brake is activated if pressure is applied against the guard or when, in the event of kickback, the operator's hand strikes the lever. In chainsaws equipped with electric motor chain movement will be stopped by cutting off the power supply; in chainsaws driven by a 2 -stroke motor, a band brake is applied on the clutch drum.

In the realized prototype in case of electric motor the alarm system operates by acting on a potentiometer, in case of a 2 -stroke motor the blockage will be integrated on existing chain brake with insertion of a

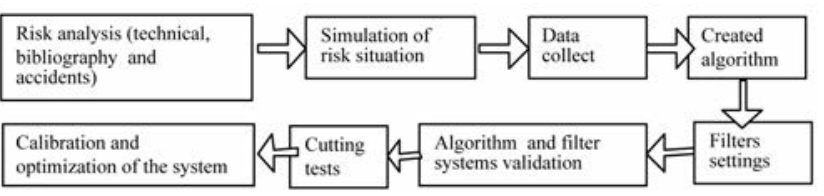

Figure 1. Flow chart of experimental procedure.

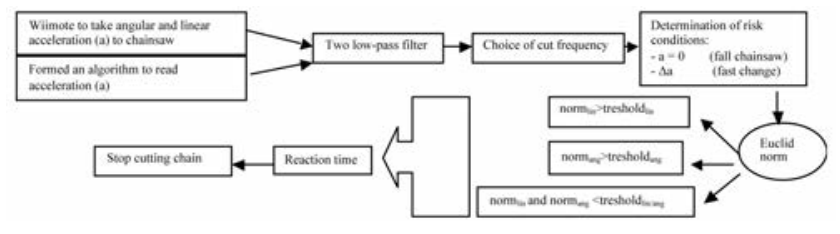

Figure 2. Scheme of algorithm steps. mechanic piston activated by the alarm system.

A cordless electric chainsaw, Black \& Decker GKC1817, 18-V 8-in was used in the tests.

Data were collected by a Wiimote controller (Nintendo ${ }^{\mathrm{TM}}$ ) but before to start with tests was necessary to define calibration parameters in order to calculate accelerations from the Wiimote output for (Wiimote reported values 0 to 999). We found this values:

- the value 490 is equal to linear acceleration zero (acclin=0);

- the value 590 is equal to linear acceleration $\mathrm{g}$ (acclin=9.8 $\mathrm{m} / \mathrm{s})$.

The test for control the level of acceleration was carried out cutting different kind of wood as reported in Table 2.

To optimize the alarm signals was necessary to setting the parameters in order to have the correct sensitivity about these parameters:

1. cut frequency of linear accelerations: cfSlin;

2. cut frequency of angular accelerations: cfSang;

3. linear threshold: thlin;

4. angular threshold: thang;

5. fall threshold: thfall.

Table 1. Technical data GKC1817 chainsaw.

\begin{tabular}{lcc}
\hline Voltage & Vdc & 18 \\
Battery capacity & $\mathrm{Ah}$ & $1.7-1.5 \mathrm{NiCd}$ \\
\hline Battery mass & $\mathrm{kg}$ & 0.8 \\
Charging time & $\mathrm{h}$ & 8 \\
\hline No load chain speed & $\mathrm{m} / \mathrm{s}$ & 3.1 \\
Guide bar length & $\mathrm{cm}$ & 20 \\
\hline Mass & $\mathrm{kg}$ & 2.8 \\
\hline
\end{tabular}

Table 2. Test to cut simulation.

\begin{tabular}{lccc} 
Wood & $\emptyset$ wood (cm) & $\begin{array}{c}\text { Replicates } \\
\text { (n.) }\end{array}$ & \multicolumn{1}{c}{ Mode of cutting } \\
Soft (poplar) & 4.0 & 29 & Up-down (lower cutting chain) \\
Medium soft (fir) & 3.3 & 16 & Up-down (lower cutting chain) \\
\hline Hard (oak) & 5.8 & 10 & Up-down (lower cutting chain) \\
Hard (oak) & 5.8 & 10 & Down-up (upper cutting chain) \\
\hline Hard (oak) & 5.8 & 10 & $\begin{array}{c}\text { Up-down (lower cutting chain, } \\
\text { near to top of guide bar) } \\
\text { Down-up (upper cutting chain, } \\
\text { near to top of guide bar) }\end{array}$ \\
\hline
\end{tabular}

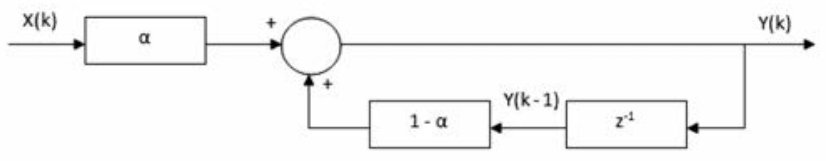

Figure 3. Scheme of low-pass filter ( $\alpha=$ parameter with range 0-1; $\mathrm{X}=$ Laplace transformed in input; $\mathrm{Y}=$ Laplace transformed in output; $\mathrm{k}=$ sample; $\mathrm{z}=\operatorname{coordinate}($ or $\mathrm{x}$ and $\mathrm{y})$ ). 


\section{Results}

The formed algorithm is capable to distinguish this risk situations:

- slipping operator;

- falling operator;

- falling chainsaw;

- kick back chainsaw;

- any another fast movements of chainsaw or operator.

The algorithm calculates the vectorial norm to linear acceleration and angular acceleration (Eq. 1 and 2).

$$
\begin{aligned}
& \operatorname{norm}_{l b n}=\sqrt{\left.a_{l x}^{*}(t) a_{l x}^{*}(t-1)\right)^{2}+\left(a_{l y}^{*}(t)-a_{l y}^{*}(t-1)\right)^{2}+\left(a_{l z}^{*}(t)-a_{l z}^{*}(t-1)\right)^{2}} \\
& n^{n o r m} m_{a n g}=\sqrt{\left.a_{a x}^{*}(t) a_{a x}^{*}(t-1)\right)^{2}+\left(a_{a y}^{*}(t)-a_{a y}^{*}(t-1)\right)^{2}+\left(a_{a z}^{*}(t)-a_{a z}^{*}(t-1)\right)^{2}}
\end{aligned}
$$

The Euclid norm sphere delimits a space where the chainsaw can be moved. If, in this delimited space, the chainsaw goes through under condition showed in Figure 2, the Wiimote stops the potentiometer to electric chainsaw.

The test carried out for verify the correct correlation to accelerations and alarm signal show:

- that the normal cutting with soft wood has a sufficient uniform linear and angular acceleration (Figure 4).

- $\quad$ the normal cutting with hard wood has a good uniformity as to linear and angular accelerations, but also has more amplitude then in the previous case (Figure 5).

- the cutting in down-up mode with upper cutting chain part do not show more amplitude in accelerations than normal cutting (Figure $6)$.

- the cutting in up-down or down-up mode near to top of guide bar the acceleration held a large amplitude but not so great to activate the alarm signal (Figure 7) .

In conclusion when the chainsaw works in different mode but always inside a normal condition the alarm signal is not activated.

The test carried out for setting parameters must result in optimized the alarm signals, not to sensitivity because the chainsaw should not be stopped so easily and not too strong.

The data collected were reported in 9 combinations both linear acceleration and angular accelerations with a number of errors reported (from 0 to $>50$ ). When cutting wood the alarm doesn't need to be activated and must be considered only those combinations where the value is equal to zero (Tabb. 4 and 5).

At the same mode were setting the parameters also in others different kind of cutting (up-down cutting chain, near to top of guide bar and down-up).

About chainsaw falling down the we know when a body fall the linear acceleration is equal to zero. The threshold value for observer this con-

Table 3. Setting of parameters sampled at $100 \mathrm{~Hz}$ by Wiimote.

\begin{tabular}{|c|c|c|c|}
\hline Hard (oak) & 5.8 & 10 & Up-down (lower cutting chain) \\
\hline Hard (oak) & 5.8 & 10 & Down-up (upper cutting chain) \\
\hline Hard (oak) & 5.8 & 10 & $\begin{array}{l}\text { Up-down (lower cutting chain, } \\
\text { near to top of guide bar) }\end{array}$ \\
\hline Hard (oak) & 5.8 & 10 & $\begin{array}{l}\text { Down-up (upper cutting chain, } \\
\text { near to top of guide bar) }\end{array}$ \\
\hline Nothing & - & 10 & Falling chainsaw \\
\hline
\end{tabular}

Wood $\quad \emptyset$ wood $(\mathrm{cm})$ Reply Kind of cutting
(n.)

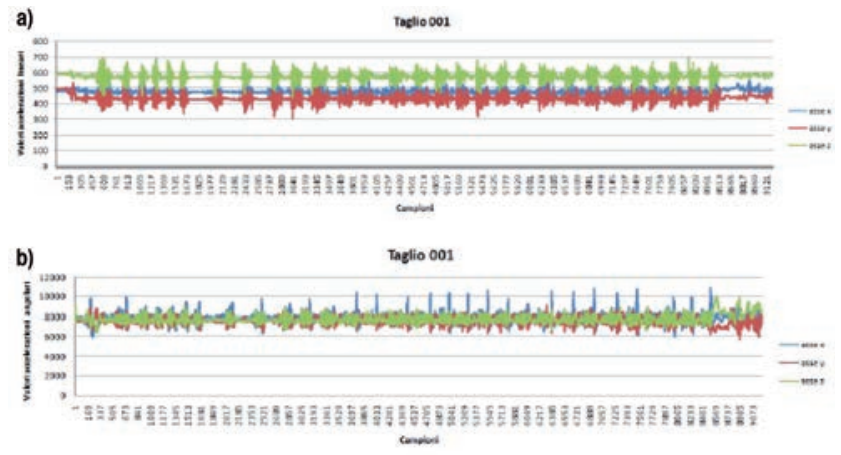

Figure 4. Linear A) and angular B) acceleration with normal cutting to soft wood (up-down with lover cutting chain).

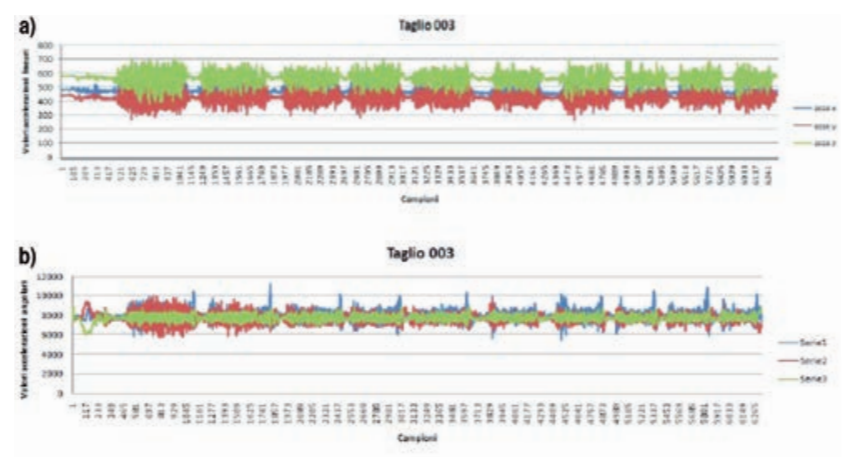

Figure 5. Linear A) and angular B) acceleration with normal cutting to hard wood (up-down with lover cutting chain).

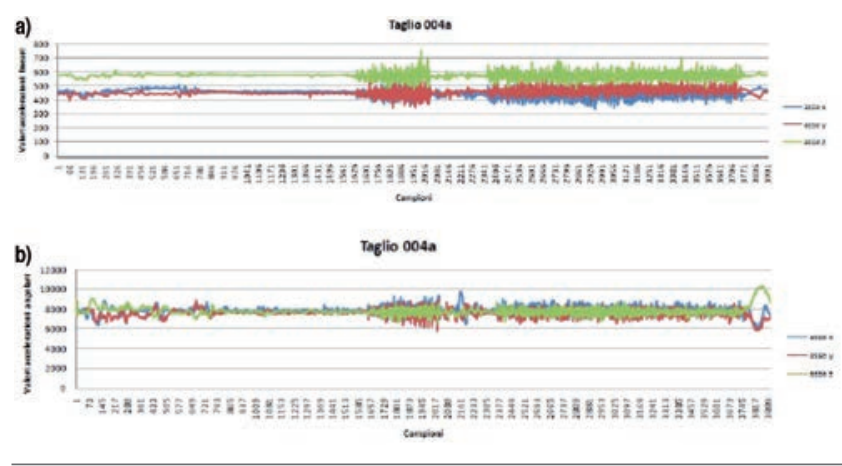

Figure 6. Linear a) and angular b) acceleration with down-up cutting to hard wood.
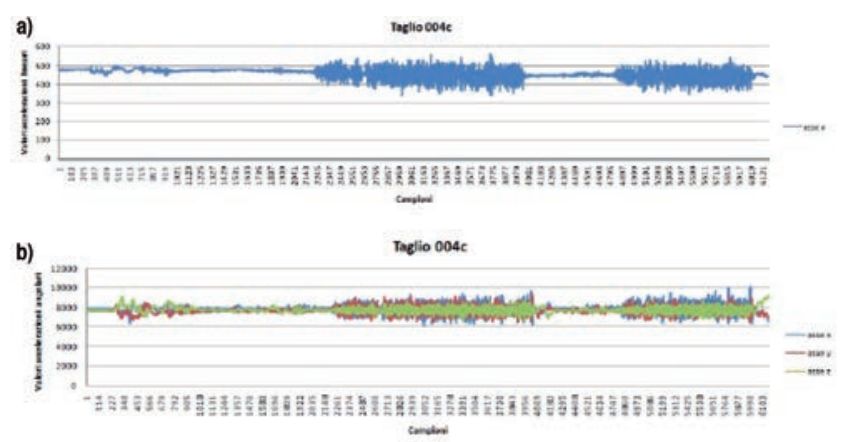

Figure 7. Linear a) and angular b) acceleration with down-up near to top of guide bar cutting to hard wood. 
Table 4. Linear cut frequency (cfSlin) and linear threshold (thlin) to cut hard wood.

\begin{tabular}{lcccc} 
& & \multicolumn{4}{c}{ Linear cut frequency } \\
& & 0.10 & 0.39 & 0.60 \\
Linear & 3 & 0 & $>50$ & $>50$ \\
Threshold & 5 & 0 & 0 & $>50$ \\
& 6 & 0 & 0 & 39 \\
\hline
\end{tabular}

Table 5. Angular cut frequency (cfAng) and angular threshold (thang) to cut hard wood.

\begin{tabular}{lcccc} 
& \multicolumn{4}{c}{ Angular cut frequency } \\
& & 0.05 & 0.45 & 0.60 \\
Angular & 50 & 1 & $>50$ & $>50$ \\
Threshold & 250 & 0 & 0 & 1 \\
& 450 & 0 & 0 & 1 \\
\hline
\end{tabular}

Table 6. Parameters setup on Wiimote.

\begin{tabular}{lc}
\hline Linear cut frequency (cflin) & 0.40 \\
Angular cut frequency (cfang) & 0.45 \\
\hline Linear threshold (Thlin) & 5 \\
Angular threshold (thang) & 250 \\
\hline Falling threshold (thfall) & 40 \\
\hline
\end{tabular}

dition must be very little and we setup the Wiimote to 40 value.

The parameters setup after test were reported in Table 6 .

\section{Conclusion and perspectives}

The device show a correct behavior in dangerous situations and it is envisable that it can be extent to combustion engine chainsaws, as well as to other portable equipment used in agriculture and forestry operations. The Wiimote is a easy and cheap device to install to the chainsaw for collect acceleration and position data. The algorithm allows the good control of processing data and send right signal to blocking cutting chain. The idea based on Wiimote device and algorithm based on Euclid norm is patented in 2011 (Blanchini et al., 2001) for have a chance to further development as a real application on chainsaw.

\section{References}

Axelsson S., 1998. The mechanization of logging operations in Sweden and its effects on occupational safety and health. J. For. Eng. 9(2): 25-31.

Blanchini F., Lombardo R., Battiston G., Cividino S.R.S., Pighin J., Gubiani R., Pergher G. (2011). Patent rif. Glp's ref. A3-8816. State, Italy, filling No. UD2011A000039. Filling date: 15/03/11. International classification B27G.

Bracchetti Montorselli N.; Lombardini C.; Magagnotti N.; Marchi E.; Neri F.; Picchi G.; Spinelli R., 2010. Relating safety, productivity and company type for motor-manual logging operations in the italian Alps. Accidents analysis and Prevention 42, 2013-2017.

Lefort A. J. Jr; de Hoop C.F.; Pine J. C.; Marx B.D., 1999. Characteristics of injuries in the Logging Industry of Louisiana, USA: 1986 to 1998. International Journal of Forestry Engineering, pp 75-89.

Hartfield J., (1997). First Standardized Federal accident statistic Analysis of accident data of the State Forest Services in Germany. Preceedings of the seminar on safety and health in forestry are feasible herld in Konolfingen, Switerland, October 6-11, 1996, pp 105126.

Husqvarna, TrioBrake ${ }^{\mathrm{TM}}$ AB. SE-104 25 Stockholm S:t Göransgatan 143 $\begin{array}{lllllll}+46-3614 & 65 & 00 & +46-88739 & 64 & 50 & 556000-5331\end{array}$ www.husqvarna.com. Sweden.

Jordan C. Friese A., Heywood P., Barber A. Patent. Application Number: EP20100195647 Publication Date: 06/20/2012 Filing Date: 12/17/2010. International classification B27B 17/08.

Poto nik I, Pentek T., Poje A. (2009). Severity analysis of accidents in forest operations. Cro. J. for. Eng. 30, 2, 171-184.

Shaffer R. M., Milburn J. S., 1999. Injuries on feller-buncher/grapple skidder logging operations in the Southeastern United States. For. Prod. J. 49 (7/8):24-26.

Zangl ,B.G, Bretterklieber T., (2008). A warning system for chainsaw personal safety based on capacitive sensing. IEEE conference "Sensors", Lecce 26-29 0ctober, pages 419-422. 